\title{
A case of unusual Gram-negative bacilli septic arthritis in an immunocompetent patient
}

\author{
Li Qi Chiü ${ }^{1}$, MBBS, MCEM, Wilson Wang², FRCSG, D Phil
}

\begin{abstract}
The Gram-negative bacilli Acinetobacter baumannii, Burkholderia cepacia, Ochrobactrum anthropi, Pseudomonas mendocina, Ralstonia spp., Serratia marcescens and Stenotrophomonas maltophilia are ubiquitous environmental organisms of low virulence, and do not usually cause illness in immunocompetent hosts. We report a case of multiple concurrent opportunistic Gram-negative bacilli causing septic arthritis in a healthy patient following trauma to the knee. Repeated operations, including arthroscopy, arthrotomy and debridement, were required before tissue cultures became negative. The patient also required an extended duration of intravenous and oral antibiotic treatment before he was discharged. Gram-negative bacillary septic arthritis is an uncommon but significant condition that requires repeated debridement and washouts in order to achieve bacterial eradication. This case report highlights the importance of an awareness of the external environment at the time of injury, as it impacts the type of organisms causing the infection, and consequently, the choice of empiric antibiotics required for successful treatment.
\end{abstract}

Keywords: arthrotomy, Gram-negative, septic arthritis, trauma

\section{INTRODUCTION}

Gram-negative bacillary septic arthritis is a relatively infrequent entity, which has sporadically appeared in the medical literature as case reports or case series. Many such incidences were reported to occur in immunocompromised patients (e.g. patients with cancer, patients with chronic debilitating illnesses, ${ }^{(1)}$ and patients of extreme age $\left.{ }^{(2)}\right)$, in patients with implants such as intravascular catheters, ${ }^{(3)}$ or via contamination of infusion and cleansing solutions in hospitals. ${ }^{(4)}$ In this case report, we present the occurrence of not one, but several concurrent opportunistic Gram-negative organisms causing septic arthritis in an immunocompetent patient, and describe the steps taken toward treatment and cure.

\section{CASE REPORT}

A 34-year-old healthy male production manager was admitted to our department following a motorcycle accident, which occurred within the area of an outdoor construction site in Singapore. His injuries included a right knee laceration with posterior cruciate ligament (PCL) avulsion fracture, degloving injury of the right foot dorsum, and right second metatarsal open fracture. On examination, there was a deep laceration over the right knee that extended into the joint, extensive soft tissue loss over the right foot dorsum, and multiple superficial abrasions on the right calf. All wounds were contaminated with dirt and soil.

The patient was commenced on intravenous cefazolin and gentamicin. He underwent right knee arthrotomy and washout, wound debridement of the right foot dorsum and vacuum-assisted closure (VAC) dressing application, and Kirshner wiring of the second metatarsal fracture on the same day. Operative findings were of an infrapatellar wound of the right knee measuring $2 \mathrm{~cm}$ and extending into the joint with laxity due to the avulsed $\mathrm{PCL}$, wounds measuring $4 \mathrm{~cm} \times 3 \mathrm{~cm}$ and $2 \mathrm{~cm} \times 1 \mathrm{~cm}$ from the degloving injury over the right foot dorsum, an avulsed extensor tendon to the second toe and an open second metatarsal fracture. All wounds were heavily contaminated.

Initial tissue cultures from the knee wound grew Acinetobacter spp. and Serratia marcescens. The antibiotics were then changed to oral ciprofloxacin by the hospital's infectious diseases referral team. Over the next two and a half weeks, the patient underwent two further foot wound debridements, a right knee arthroscopic washout and further arthrotomy. Right knee arthroscopy, debridement, synovial biopsy and synovectomy were performed 11 days after the initial operation. Findings were of florid inflamed synovitis and cloudy, but nonpurulent, joint fluid. There was a large area of medial femoral condyle chondral damage with flap tear and fibrillation. There was no evidence of biofilm formation, and the impression then was that the changes were likely postsurgical. Subsequent knee tissue cultures, arthroscopic washout samples and foot wound cultures grew Acinetobacter baumannii, Burkholderia cepacia, Ochrobactrum anthropi, Pseudomonas mendocina, Ralstonia spp. and Stenotrophomonas maltophilia. Hence, the patient's antibiotic therapy was changed to oral co-trimoxazole.

${ }^{1}$ Emergency Medicine Department, ${ }^{2}$ University Orthopaedics, Hand and Microsurgery Cluster, National University Health System, Singapore

Correspondence: Dr Chiu LQ, Registrar, Emergency Medicine Department, National University Health System, 5 Lower Kent Ridge Road, Singapore 119074. chiuliqi@gmail.com 
Table I. Culture results and sensitivities of organisms cultured from samples obtained during the various operations.

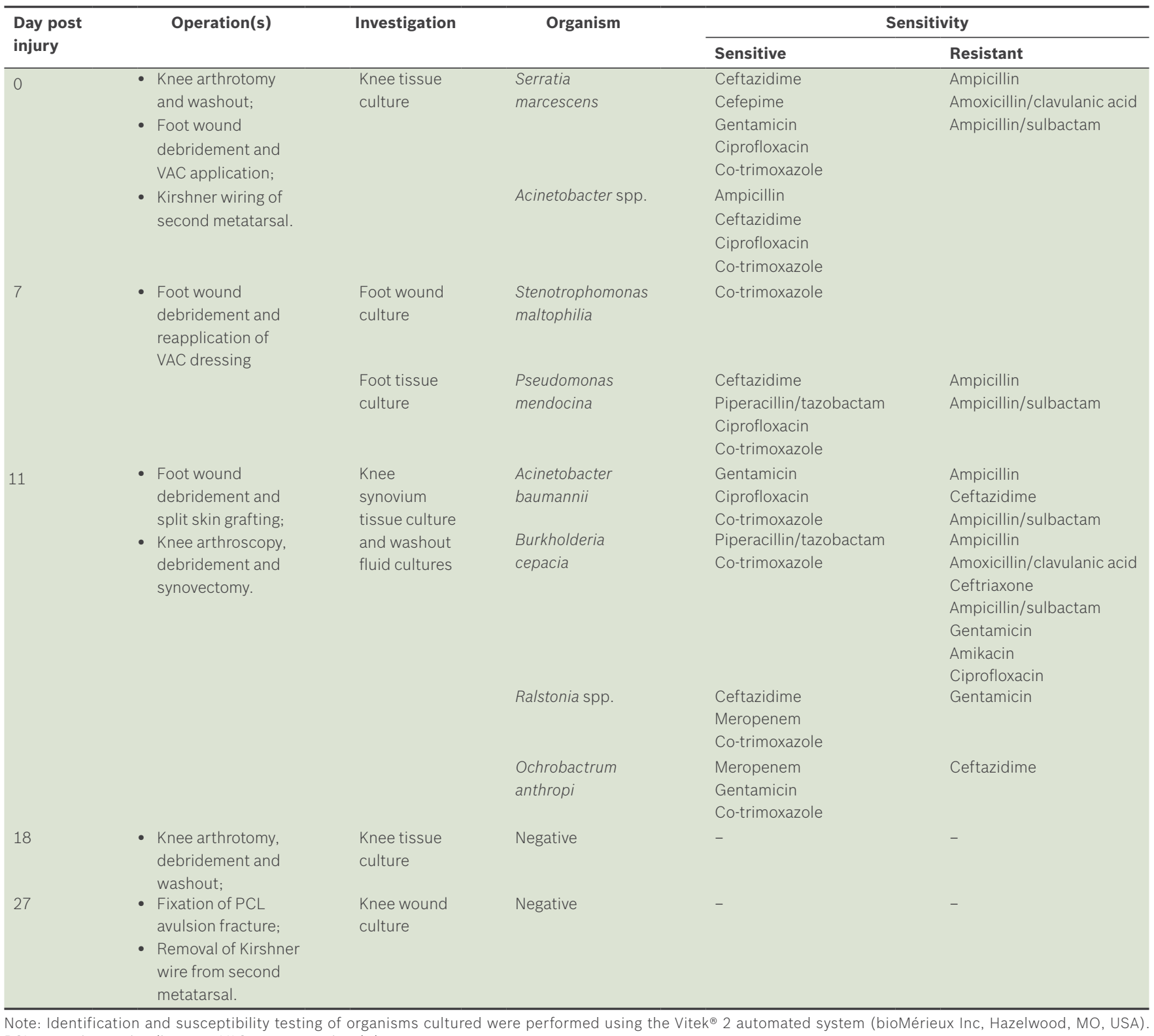

PCL: posterior cruciate ligament; VAC: vacuum-assisted closure

Table I lists the details of the operations that the patient underwent, the tissue and arthroscopic washout samples' culture results, and the detected organisms' sensitivities. All tissue samples were first subjected to Gram staining. After which, the tissue samples were inoculated onto solid media (sheep blood, MacConkey and chocolate agar plates) to be incubated aerobically in $5 \%$ carbon dioxide for 24 hours, and onto CDC and neomycin plates to be incubated for 48 hours in anaerobic conditions. Identification and susceptibility testing of organisms cultured were then performed using the Vitek ${ }^{\circledR} 2$ automated system (bioMérieux Inc, Hazelwood, MO, USA). Laboratory findings revealed elevated white blood cell count $\left(14,770 / \mathrm{mm}^{3}\right)$, C-reactive protein $(16 \mathrm{mg} / \mathrm{L})$ and erythrocyte sedimentation rate (33 mm/hr). Blood cultures did not reveal any bacterial growth; however, these were drawn more than 72 hours after the commencement of intravenous antibiotic therapy.
The patient remained afebrile and nontoxic throughout the course of antibiotic therapy. Follow-up blood investigations showed normalisation of the white blood cell count and inflammatory markers.

Notably, four organisms (Acinetobacter baumannii, Burkholderia cepacia, Ochrobactrum anthropi and Ralstonia spp.) that are rarely found in patients who are not immunosuppressed were isolated from the synovium tissue samples and arthroscopic washouts of our patient. This led to the decision of a repeat arthrotomy. Findings of the repeat operation were turbid haemoserous joint fluid and exuberant synovitis. No frank pus or biofilm formation was observed. Full washout was achieved using $12 \mathrm{~L}$ of saline, with the knee balloted in a flexed position to achieve optimal washout of the posterior fossa. At the same time, the patient was screened for human immunodeficiency viral (HIV) infection; results showed that the patient was HIV negative. All tissue 
Table II. Studies reporting Gram-negative bacillary septic arthritis.

\begin{tabular}{|c|c|c|c|c|c|c|c|}
\hline Organism & Study & Year & $\begin{array}{l}\text { Age } \\
\text { (yrs) }\end{array}$ & Joint & $\begin{array}{l}\text { Contributing } \\
\text { factor }\end{array}$ & Treatment & Outcome \\
\hline $\begin{array}{l}\text { Acinetobacter } \\
\text { baumannii }\end{array}$ & Duan et $\mathrm{al}^{(7)}$ & 2010 & 40 & Knee & $\begin{array}{l}\text { Gouty arthritis } \\
\text { Alcohol intake }\end{array}$ & $\begin{array}{l}\text { IV polymyxin } \\
\text { Surgical drainage }\end{array}$ & Cured \\
\hline \multirow[t]{3}{*}{$\begin{array}{l}\text { Burkholderia } \\
\text { cepacia }\end{array}$} & Kothari et a|(8) & 1977 & 58 & Ankle & $\begin{array}{l}\text { Intra-articular } \\
\text { injection of steroid }\end{array}$ & $\begin{array}{l}\text { IV gentamicin } \\
\text { Serial aspirations }\end{array}$ & Cured \\
\hline & Matteson et al(9) & 1990 & 72 & Knee & $\begin{array}{l}\text { Intra-articular } \\
\text { injection of steroid }\end{array}$ & $\begin{array}{l}\text { IV chloramphenicol } \\
\text { IV ceftazidime } \\
\text { Surgical drainage }\end{array}$ & Cured \\
\hline & Miki et al(10) & 2006 & 65 & Shoulder & T-cell lymphoma & $\begin{array}{l}\text { IV ceftriaxone } \\
\text { Surgical drainage }\end{array}$ & Death \\
\hline \multirow[t]{2}{*}{$\begin{array}{l}\text { Ochrobactrum } \\
\text { anthropi }\end{array}$} & Saveli et al $\left.\right|^{(11)}$ & 2007 & 53 & $\begin{array}{l}\text { Wrist } \\
\text { Knee }\end{array}$ & $\begin{array}{l}\text { Gout } \\
\text { Alcohol intake } \\
\text { Repair of knee ligaments }\end{array}$ & $\begin{array}{l}\text { Oral co-trimoxazole } \\
\text { Surgical drainage }\end{array}$ & Cured \\
\hline & Battaglia $^{(12)}$ & 2008 & 17 & Acromioclavicular & Trauma & $\begin{array}{l}\text { Oral ciprofloxacin } \\
\text { Oral co-trimoxazole } \\
\text { Surgical excision }\end{array}$ & Cured \\
\hline \multirow[t]{2}{*}{$\begin{array}{l}\text { Ralstonia } \\
\text { pickettii }\end{array}$} & Zellweger et al(13) & 2004 & 24 & $\begin{array}{l}\text { Elbow } \\
\text { Knee }\end{array}$ & Intravenous drug user & $\begin{array}{l}\text { Oral ciprofloxacin } \\
\text { Surgical drainage }\end{array}$ & Cured \\
\hline & Makaritsis et al(14) & 2006 & 83 & Knee & $\begin{array}{l}\text { Diabetes mellitus } \\
\text { Hypertension } \\
\text { Ischaemic stroke }\end{array}$ & $\begin{array}{l}\text { IV ceftazidime } \\
\text { Single aspiration }\end{array}$ & Cured \\
\hline \multirow[t]{2}{*}{$\begin{array}{l}\text { Stenotrophomonas } \\
\text { maltophilia }\end{array}$} & Belzunequi et al(15) & 2000 & 36 & Knee & AIDS & $\begin{array}{l}\text { Oral ciprofloxacin } \\
\text { Oral co-trimoxazole } \\
\text { Single aspiration }\end{array}$ & Cured \\
\hline & Avdemir et al(16) & 2008 & 8 & Knee & Trauma & $\begin{array}{l}\text { IV amikacin } \\
\text { Oral co-trimoxazole } \\
\text { Surgical drainage }\end{array}$ & Cured \\
\hline
\end{tabular}

AIDS: acquired immunodeficiency syndrome; IV: intravenous

cultures from the operation performed 18 days after the day of injury were negative. Four weeks after the accident, the patient underwent fixation of the PCL avulsion fracture with cancellous screw and washer, as well as removal of the Kirshner wire from the metatarsal. Oral co-trimoxazole was stopped after intraoperative cultures revealed no bacterial growth. At an outpatient review three months after the initial injury, the patient was clinically well but his knee had a significantly decreased range of motion, for which he required intensive rehabilitation.

\section{DISCUSSION}

Infections following trauma are often polymicrobial. According to the literature, predominantly isolated aerobic microorganisms include Escherichia coli, Staphylococcus aureus, Streptococcus pyogenes, Streptococcus group D and Klebsiella pneumonia, while predominantly isolated anaerobic microorganisms include Peptostreptococcus spp., Clostridium spp., Prevotella spp., Fusobacterium spp. and Bacteroides fragilis. ${ }^{(5)}$ In contrast, the organisms isolated in our patient's tissue cultures are uncommon causes of traumatic wound infections. Among the seven organisms isolated from our patient's tissue cultures, only Serratia marcescens is well documented as a cause of septic arthritis, with the earliest case reported in 1968. ${ }^{(6)}$ The other organisms isolated from our patient's tissue cultures (i.e. Acinetobacter baumannii, Burkholderia cepacia, Ochrobactrum anthropi, Pseudomonas mendocina, Ralstonia spp. and Stenotrophomonas maltophilia) were Gram-negative organisms that are ubiquitous in the environment. These organisms are known to have low virulence and generally do not cause illness in immunocompetent persons. However, the literature has shown an increasing, albeit limited, number of reports where these organisms cause significant illness in their immunocompetent hosts.

Table II summarises other cases of septic arthritis caused by the same Gram-negative organisms that were isolated from our patient's tissue cultures. Of the ten cases of septic arthritis due to Gram-negative organisms, seven occurred in the knee and all except one were diagnosed based on joint aspiration. ${ }^{(12)}$ In more than half of the cases, a risk factor for an immunosuppressed state was present. Trauma, which was the causative factor in the present case, was also the causative factor in four cases. Surgery was the mainstay of treatment for seven of the ten cases, with three cases treated by aspiration, ${ }^{(8,14-15)}$ and one via excision arthroplasty (acromioclavicular joint). ${ }^{(12)}$ All patients but one were cured; that patient died due to multifactorial contributions of advanced age, recurrent malignancy and immunosuppression. ${ }^{(10)}$ Compared to Gram-negative bacteraemia, which is well known in the medical literature, Gram-negative bacillary septic arthritis is not as well reported. Aside from a review by Bayer et al in 1977,(17) only sporadic cases of septic arthritis due to Gram-negative organisms have been reported. It is important to recognise that septic arthritis 
caused by Gram-negative bacteria has poorer reported outcomes than those caused by Gram-positive bacteria. In Gram-negative bacillary septic arthritis, a lower cure rate, poorer therapeutic results, recurrent infection, secondary osteomyelitis, flexion contractures, chronic effusions, and joint ankylosis, have been reported ${ }^{(17)}$ The review also emphasised the importance of surgical drainage, as it is considered to be the best treatment for septic arthritis.

Our report highlights the need for an awareness of such unusual organisms in wounds sustained in a dirty external environment, so that appropriate antibiotics are prescribed for empirical cover. Furthermore, antibiotic susceptibilities are variable, further contributing to the difficulty in choosing appropriate antibiotics for the treatment of traumatic wounds with significant soilage. In our case, the intravenous gentamicin and cephazolin that were used in the initial drug therapy proved insufficient to eradicate most of the soil-based organisms isolated in the patient. However, co-trimoxazole, which was subsequently used, was successfully used as the mainstay therapy for the patient. Co-trimoxazole, also known as trimethoprim sulfamethoxazole, is effective against a wide variety of aerobic Gram-positive and Gram-negative bacteria; it also inhibits pathogens such as Burkholderia cepacia, Stenotrophomonas maltophilia and Serratia marcescens, all of which were isolated in our patient's tissue cultures. Although there have been isolated case reports and small case series demonstrating the use of co-trimoxazole in septic arthritis, the Infectious Diseases Society of America (IDSA) guidelines only recommend the use of co-trimoxazole for outpatient empirical coverage of community-acquired methicillin-resistant Staphylococcus aureus skin and soft tissue infections, where it has been shown to be effective. ${ }^{(18)}$

In 2011, IDSA published a set of guidelines regarding the prevention of infections associated with combat-related injuries. Combat-related injuries often involve exposure to an external environment that is highly contaminated with soil organisms, which is also the case for most orthopaedic injuries. Such injuries are often complex and associated with extensive tissue destruction and high risk for early and remote infectious complications. Systemic antimicrobials should be administered as soon as possible post injury, ideally within three hours, and the antimicrobial selection should focus on providing the narrowest spectrum of activity required. The antibiotic of choice in extremity injuries (i.e. skin, soft tissue and/or bone) is intravenous cefazolin 2 g every $6-8$ hours, or intravenous clindamycin $600 \mathrm{mg}$ every 8 hours for a duration of 1-3 days (level IB evidence). Enhanced Gram-negative coverage should not be employed (level IB evidence) and the addition of penicillin is not required (level IC evidence). ${ }^{(19)}$ Nevertheless, it is worth considering co-trimoxazole as part of the empiric antibiotic therapy for future patients sustaining injuries in a contaminated external environment similar to our present case.
We also wish to highlight the tenacity of these Gramnegative organisms, which grew in cultures taken after repeated joint washouts. It is thus important to recognise that thorough, and possibly, repeated surgeries are required to eradicate these organisms and restore a sterile environment. Our patient required no fewer than three joint washouts to achieve negative cultures, before we could proceed with fixation of the PCL avulsed fragment. Gram-negative bacillary septic arthritis is an uncommon but significant orthopaedic infection, in which surgery and a prolonged course of antibiotics, followed by intensive physiotherapy, is required to successfully treat the disease, as well as to minimise long-term complications.

\section{ACKNOWLEDGMENTS}

We would like to thank Dr Chan SG Douglas for providing us with information regarding microorganism identification and the antibiotic susceptibility tests of the hospital's microbiology laboratory.

\section{REFERENCES}

1. Yu WL, Lin CW, Wang DY. Clinical and microbiologic characteristics of Ochrobactrum anthropi bacteraemia. J Formos Med Assoc 1998; 97:106-12.

2. Kimura AC, Calvet H, Higa J, et al. Outbreak of Ralstonia pickettii bacteremia in a neonatal intensive care unit. Pediatr Infect Dis J 2005; 24:1099-103.

3. Mahmood MS, Sarwari AR, Khan MA, et al. Infective endocarditis and septic embolisation with Ochrobactrum anthropi: case report and review of literature. J Infect 2000; 40:287-90.

4. Ryan MP, Pembroke JT, Adley CC. Ralstonia pickettii: a persistent gramnegative nocosomial infectious organism. J Hosp Infect 2006; 62:278-84.

5. Brook I, Frazier EH. Aerobic and anaerobic microbiology of infection after trauma. Am J Emerg Med 1998; 16:585-91.

6. Atlas E, Belding ME. Serratia marcescens arthritis requiring amputation. JAMA 1968; 204:167-9.

7. Duan X, Yang L, Xia P. Septic arthritis of the knee caused by antibioticresistant Acinetobacter baumannii in a gout patient: a rare case report. Arch Orthop Trauma Surg 2010; 130:381-4.

8. Kothari T, Reyes MP, Brooks N. Pseudomonas cepacia septic arthritis due to intra-articular injections of methylprednisolone. Can Med Assoc J 1977; 116:1230, 1232, 1235.

9. Matteson EL, McCune WJ. Septic arthritis caused by treatment-resistant Pseudomonas cepacia. Ann Rheum Dis 1990; 49:258-9.

10. Miki RA, Rubin LE, Kirk J, Dodds SD. Spontaneous septic arthritis caused by Burkholderia cepacia. lowa Orthop J 2006; 26:147-50.

11. Saveli CC, Levi M, Koeppe J. Ochrobactrum anthropi septic arthritis: case report and implications in orthopedic infections. Infectious Disease Reports 2010; 2:e2.

12. Battaglia TC. Ochrobactrum anthropi septic arthritis of the acromioclavicular joint in an immunocompetent 17 year old. Orthopedics 2008; 31:606.

13. Zellweger C, Bodmer T, Täuber MG, Mühlemann K. Failure of ceftriaxone in an intravenous drug user with invasive infection due to Ralstonia pickettii. Infection 2004; 32:246-8.

14. Makaritsis KP, Neocleous C, Gatselis N, Petinaki E, Dalekos GN. An immunocompetent patient presenting with severe septic arthritis due to Ralstonia pickettii identified by molecular-based assays: a case report. Cases J 2009; 2:8125.

15. Belzunequi J, De Dios JR, Intxausti JJ, Iribarren JA. Septic arthritis caused by Stenotrophomonas maltophilia in a patient with acquired 
immunodeficiency syndrome. Clin Exp Rheumatol 2000; 18:265.

16. Avdemir C, Aktas E, Eldes N, et al. Community-acquired infection due to Stenotrophomonas maltophilia: a rare cause of septic arthritis. Turk J Pediatr 2008; 50:89-90.

17. Bayer AS, Chow AW, Louie JS, Nies KM, Guze LB. Gram-negative bacillary septic arthritis: clinical, radiographic, therapeutic, and prognostic features. Semin Arthritis Rheum 1977; 7:12-32.

18. Liu C, Bayer A, Cosgrove SE, et al. Clinical practice guidelines by the infectious diseases society of America for the treatment of methicillin-resistant Staphylococcus aureus infections in adults and children. Clin Infect Dis. 2011; 52:e18-55.

19. Hospenthal DR, Murray CK, Andersen RC, et al. Guidelines for the prevention of infections associated with combat-related injuries: 2011 update: endorsed by the Infectious Diseases Society of American and the Surgical Infection Society. J Trauma. 2011; 71:S210-34. 